\title{
Vanguardia peruana o Vanguardia de peruanos
}

Alfredo BUSHBY

Laurietz Seda y Rubén Quiroz (eds). Travesías trifrontes. El teatro de vanguardia en el Perú, Lima: Fondo Editorial de la UNMSM, 2008.

Tal vez, el mérito más visible de este estudio y recopilación de textos dramáticos es haber rescatado de una posible desaparición dramas que, sin este esfuerzo, habrían permanecido (a veces, literalmente) en cajas cerradas por décadas (quizás hasta que bien intencionadas generaciones futuras hubieran donado el papel para reciclaje). En este sentido, son dignos de mención los viajes, las pesquisas, y la capacidad de persuasión de los editores, Laurietz Seda y Rubén Quiroz, para conseguir y publicar estos textos. Hablo especialmente de dos de las tres obras recopiladas: 13 Club. Tragi-comedia en 3 actos y medio (1929) de Luis Berninsone y de Caperucita encarnada de (1956) de Joel Marrokín, ya que las tercera obra de esta colección -Ojo de perdiz (1940) de César Moro- ya había sido "rescatada" y traducida del francés por Ricardo Silva Santisteban en el 2002 como Ojo de gallo. Sin embargo, se puede decir que la obra de Moro también fue, en cierto sentido, rescatada en Travesías trifrontes, ya que el libro nos presenta una nueva traducción de la obra, traducción que, según sus editores, le da un "mayor sentido poético" (p. 31) a la pieza.

Definitivamente, como mencioné, el rescate de estos textos es el mérito que más salta a la vista. Pero está lejos de ser el único o el más importante. Quiero concentrarme en otro logro, un logro más sutil (tal vez, inclusive, inconsciente), un mérito que, desde una perspectiva distinta, pueda considerarse un demérito: el haber puesto sobre la mesa de discusión la pregunta de si existió o no un teatro peruano de Vanguardia. La respuesta de los editores, en su informado estudio introductorio, es tajante: sí existió tal teatro, y, si hasta ahora no se le ha dado el reconocimiento que merece, 
no es por falta de obras sino por desidia académica; y ahí están los textos de Berninsone, Moro, Marrokín y otros para probarlo.

Sin pretender dar una respuesta a la pregunta, asumiré provisionalmente el cínico (aunque necesario) rol de abogado del diablo. Para hacerlo, reformularé la pregunta hecha anteriormente: ¿se puede decir que existió un teatro peruano de Vanguardia cuando, en la mayoría de los ejemplos mencionados, las obras no fueron puestas en escena durante la vida de los autores (y algunas aún permanecen sin montarse), cuando, en la mayoría de los casos, las piezas fueron escritas en el extranjero, cuando, en algunos casos, no fueron escritas en castellano, cuando, en muchas ocasiones, los autores de estas obras no eran dramaturgos "a tiempo completo" sino poetas o narradores que, ocasionalmente, escribieron una que otra obra dramática? Repito que no pretendo dar una respuesta a esta pregunta sino, antes bien, colaborar, con esta lista de "agravantes", en el debate sobre el teatro peruano de Vanguardia que Seda y Quiroz, afortunadamente, han sacado a la luz.

Sin embargo, continuando con mi rol, mencionaré podría ocurrir que no hubiera un teatro peruano de Vanguardia sino, que más bien, lo que existe es un conjunto de obras dramáticas escritas por peruanos que tienen características vanguardistas. Me explico: el concepto "teatro peruano de Vanguardia" puede, en una de sus acepciones, ser considerado como un movimiento, de alguna manera, unitario, en que habría cierta comunidad de intereses, temas, estilos o ideologías entre los autores, aunque no necesariamente una comunicación o una agenda común entre éstos. Esto último no existió en lo referente al teatro peruano (o, tal vez, debería decir, a su "dramaturgia"). ¿Cuestiona este hecho la tesis de Seda y Quiroz? La mesa está servida para el debate.

Pero, por otro lado, el hecho de que, pese a la falta de cierta unidad, a la ausencia de representaciones, a la dispersión geográfica de los autores, a que sean poetas o narradores que "en sus ratos libres" escribieron dramas, pese a todo esto, existan obras dramáticas de Vanguardia escritas por peruanos (y no pocas), puede ser (en otra acepción del concepto) prueba suficiente de la existencia un teatro peruano de Vanguardia.

Lo repito: el sacar al aire este debate que aquí he simplificado es, a mi entender, uno de los méritos más notables de Travesías trifrontes. Independientemente de la posición que se tome respecto de la existencia de un teatro peruano de Vanguardia, se esté o no de acuerdo con los editores, nunca se podrá minimizar el hecho de que la tesis de Seda y Quiroz remecerá la convención académica de que no hubo (o que fue irrelevante) tal tipo de dramaturgia entre los peruanos.

Y, ya que estamos en el tema de la Vanguardia, permítaseme subrayar otro elemento destacable del estudio preliminar de este libro. Los editores (muy 
inteligentemente, a mi parecer) no se estancan en discusiones etéreas y eternas sobre qué es la Vanguardia. Este tipo de debate -que, en algunos casos, puede volverse espiral e interminable- no era pertinente para los propósitos del libro. No digo, con esto, que un debate sobre la definición de la Vanguardia no pueda ser revelador y entusiasmante; sólo digo que la introducción de este libro no habría sido el lugar adecuado para hacerlo. Con pertinencia, los editores de Travesías trifrontes recurren a las definiciones y características dadas por Reverte Bernal y Vicky Unruh sobre lo vanguardista en el teatro y a ellas se acogen: "el eclecticismo; la ruptura con el mimetismo; el uso del metateatro [...] y de distintos lenguajes escénicos [...]; quiebre de la estructura tradicional de tres actos y del desarrollo lineal; renovado interés por la tragedia como género dramático y por la reinterpretación de grandes mitos clásicos, así como la nacionalización de temas y mitos universales [...] ... las implicaciones teóricas del mismo proceso teatral" (p. 13).

Sin embargo -y aquí paso nuevamente al detestable papel de advocatus diaboli o Promotor de la Fe- debo mencionar un rasgo de la dramaturgia de Vanguardia que escapó a la vista de los editores y que encontramos flagrantemente en los textos recopilados: la ausencia o minimización de la acción dramática. La acción es la dictadora del teatro tradicional desde los primeros dramaturgos sobre los que hablara Aristóteles hasta nuestros días. De cuando en cuando, en la historia del teatro universal, la tiranía de esta dictadora es puesta en tela de juicio. Todos los intentos de rebelión son finalmente aplastados; incluso, hoy en día, la tiranía de la acción dramática campea de manera que cualquier intento de sublevación es ignorado o ridiculizado. Sin embargo, la memoria de sus esfuerzos queda intacta en la historia de las tablas. Y esta forma de sublevación -que llegó a su apogeo con el Teatro del absurdo- fue anticipada por el teatro de Vanguardia.

Pues bien, las tres obras recopiladas por Seda y Quiroz muestran, aunque de manera diversa, este intento por zafarse de la tradición y dictadura de la primacía de la acción dramática. Estos intentos me servirán de base para hablar brevemente de las obras compiladas.

13 Club de Berninsone tiene todos los ingredientes para ser una obra en que la acción dramática sea central: una sociedad secreta de la cual uno de sus miembros trata de huir, y es perseguido (y encontrado) por uno de los integrantes de la secta para un enfrentamiento final. ¿Hay trama que potencialmente tenga más acción que la descrita? Tal vez no la haya; pero el hecho es que Berninsone no está interesado en resaltar las acciones; es más, se podría decir que la trama no es más que un pretexto para plantear situaciones que parodian una sociedad futurista. Dicho de otro modo, a Berninsone no le interesa la acción, le interesa el retrato estático de contextos, le interesa más mostrar, por ejemplo, una sociedad en la 
que los matrimonios múltiples son cosa de todos los días o en la que los locos de un manicomio son más racionales que los supuestamente sanos. El enfrentamiento final entre el protagonista y su perseguidor no sólo se minimiza hasta hacerlo irrelevante, sino que se realiza fuera de escena. Repito: la trama (la acción) en esta obra es sólo un pretexto para la parodia de un conjunto de situaciones estáticas.

Si se tratara de buscar una acción o de describir la trama de Ojo de perdiz, posiblemente distintos entusiastas llegaría a muy distintas conclusiones; y es bastante probable que algunos se resignaran a la frase "no hay trama". Puede sonar facilista, pero yo resumiría la trama como la de cinco personajes en busca de amor. Sin embargo, esta búsqueda no es, de ninguna manera, evidente; porque así como Berninsone ponía el énfasis en el retrato de situaciones, César Moro parece volcar todo su interés en el lenguaje. No quiero caer en el lugar común de decir que "el lenguaje es el protagonista", pero es evidente que la intención del autor es poética y no dramática. Y se trata de una poesía cautivante -como a la que nos tiene acostumbrados César Moro. Ojo de perdiz es, pues, una obra en que las acciones (si las hay) están absolutamente subordinadas a la sublimidad del lenguaje.

Retrato de situaciones estáticas y primacía del lenguaje poético; están son las dos formas en que los autores de 13 club y Ojo de perdiz, respectivamente, se enfrentan a la dictadura de la acción. Pero, ¿cómo lo hace Joel Marrokín en Caperucita encarnada? Utiliza ambos procedimientos: retrato estático y poesía. La trama de esta obra es la de la Caperucita roja (aunque con un giro inesperado en el final). Y si el popular cuento para niños ha cautivado la atención de lectores y oyentes por siglos es, entre otras cosas, porque tiene una clara y definida acción dramática: se sabe claramente qué quiere Caperucita y sus ayudantes, y qué quiere su oponente, el lobo. Sin embargo, Marrokín aborda esta historia posponiendo, siempre posponiendo, con el retrato de situaciones y paisajes, el avance de la acción. Y lo hace a través de una parodia del leguaje poético barroco; tan consciente, que, en algún momento, el mismo Luis de Góngora aparece como personaje. Incluso, en una escena, el mismo autor se burla de su dilatación de la trama y hace que un personaje le increpe al Coro y al Comentador (ial autor?): "Así, acabarás con la paciencia / del público, que hace rato espera / oír y ver intacta la quimera, / libre y limpia de tu impertinencia / rellena de erudiciones..." (p. 144). La respuesta del Comentador nos da una clave para una interpretación del texto en su conjunto: no es el cuento de la Caperucita el que se quiere contar o representar, lo que se quiere es buscar, detrás de la trama y los personajes del cuento, su vínculo con fuerzas naturales o sobrenaturales ("que tenemos previsto hallar / la clave solar / del cuento abracadabrante" dice el Comentador (p. 145)). Es decir, la acción de los avatares de la Caperucita y el Lobo queda minimizada (prácticamente, se 
desvanece) frente a una acción paradójicamente intelectual y mística, que, como bien reflexiona Marrokín, puede exasperar a un espectador ávido de acciones menos sutiles.

Es así que, a mi entender, la ausencia o minimización de la acción dramática debe estar incluida en la relación de características del teatro de Vanguardia. Y, por supuesto, esta consideración debería ser parte del debate que (ojalá) se suscite a partir de la publicación de este estudio y compilación de textos. Lo repito por última vez para no caer pesado: dentro de todos los méritos que podemos extraer de Travesías trifrontes, el más relevante es encender la polémica sobre la existencia o no de una dramaturgia peruana de Vanguardia 0 , tal vez, sobre una dramaturgia de Vanguardia escrita por peruanos. 